\title{
Analyzing Emergency Capacity Shortage in Urban CI Based on Scenario Presuming Method
}

\author{
Tianchang LIU \\ School of Management, \\ Harbin Institute of Technology, \\ No. 92, Xidazhi Street, Harbin, Heilongjiang, China \\ e-mail: brandon2014@163.com
}

\author{
Xiangyang LI \\ School of Management, \\ Harbin Institute of Technology, \\ No. 92, Xidazhi Street, Harbin, Heilongjiang, China \\ e-mail: xiangyangli@hit.edu.cn
}

\author{
Zhaoge LIU ${ }^{\mathrm{c}, *}$ \\ School of Management, \\ Harbin Institute of Technology, \\ No. 92, Xidazhi Street, Harbin, Heilongjiang, China \\ e-mail: zhaogeliu@hit.edu.cn
}

\begin{abstract}
CI (Critical infrastructure) is a kind of complex and huge network system, and its operating failure will cause serious impact on national interest. Evaluating emergency capacity from the perspective of capacity shortage helps directly discover the weak links of response system, and improve the effectiveness of capacity evaluation. Under the background of scenario uncertainty, it's hard to predict disaster scenarios in the future. That causes the difficulty of presuming scenarios for capacity shortage analysis. This paper proposes a presuming-based method for analyzing capacity shortage in terms of capacity shortage evaluation and identification. This method solves the scenario uncertainty of capacity shortage analysis by scenario design and reconstruction. Finally, a case study is proposed to explain the rationality and effectiveness of the method.
\end{abstract}

Keywords-urban CI; emergency capacity shortage; scenario presuming; complex system

\section{INTRODUCTION}

Critical infrastructure is the general term of multiple complex and huge network systems, including electric power, telecom, traffic, energy transportation, finance, public health and emergency service. Nowadays, fast development of urbanization makes people more dependent on the service provided by critical infrastructure. The failure of critical infrastructure will produce significant impact on national interests, including security, the economy and basic human needs [1]. However, anthropogenic and natural disasters threaten countries all around the world, and critical infrastructure can be affected easily, which causes operating failure [2]. Because of the burstiness and uncertainty of disaster scenarios, it is hard to guarantee the effectiveness of capacity evaluation from the perspective of capacity possession. Instead, evaluating from the perspective of capacity shortage can help directly discover the weak links of response systems and improve capacity evaluation effectiveness.
Emergency response is dependent on scenarios, and the estimation shortage of preparedness plan is normal. We have to acknowledge that all disasters can derive from dynamic environment. Plans can not include all the possible conditions related to future disasters [3]. For example, in 2016, heavy rainfall areas of typhoon Meranti and Megi overlapped and caused disaster plus disaster. That are what emergency management departments do not predict [4]. In 15th, October, 2009, American president Obama visited New Orleans and deeply reflected the emergency work of hurricane Katrina 4 years ago. The destruction what hurricane Katrina caused not only derive from natural disaster, the government failure, preparedness shortage and action shortage are more important [5]. However, if the risk that the dynamic environment brings overweighs the tolerance ranges and risk standards of hazard-affected bodies, we should adopt proper measures to reduce the risk. In terms of emergency response, it's necessary to make the key links redundant.

Under the background of scenario uncertainty, it is hard to predict the scenarios of future disasters directly, which causes the difficulty of scenario presetting for capacity shortage analysis. This paper proposes a presuming-based method for analyzing capacity shortage in terms of capacity shortage evaluation and identification. This method solves the scenario uncertainty of capacity shortage analysis by scenario design and reconstruction.

\section{Scenario Presuming Method IN SCENARIO UNCERTAINTY PROBLEM SOLVING}

Scenario presuming for capacity shortage analysis refers to analyzing and planning scenarios with knowledge resource such as cases and files to construct capacity shortage analyzing scenarios which adapt to real demands, including creating new scenarios and modifying existing scenarios. Scenario presuming considers the fuzziness and uncertainty of disasters and the demands of decision makers about emergency effectiveness. It is of vital importance in 
solving disaster scenario uncertainty problem. Scenario presuming method generally includes steps as follows, that are disaster scenario design, scenario presuming and presetting, scenario applying and emergency preparedness planning.

- Disaster scenario design. Disaster scenario design means to insert scenario elements or attributes for scenario presuming combing the specific kinds of disasters. The scenarios in this paper mainly consider three dimensions that are causing dimension, environment dimension and affected dimension.

- Scenario presuming and presetting. Scenario presuming and presetting refers to identifying the basic scenarios and principles of scenario presuming with emergency management demands and knowledge resource such as cases and files, finally finishing scenario presetting. Scenario presuming and presetting is the key step of scenario presuming. Its key thinking is to convert uncertain scenarios to unique scenarios or scenario vectors. Under the unique scenarios, the presuming scenarios are certain and unique, they can be used as presetting scenarios directly. Under the scenario vectors, the presuming scenarios are not unique but limited. They discretize the possible disaster scenarios in the future.

- Scenario applying and emergency preparedness planning. Scenario applying and emergency preparedness planning is to carry on emergency projects or task planning surrounding presetting scenarios. This paper applies scenario presuming method to the mining of capacity shortage problems of CI emergency. That is equal to analyze the weak links of emergency response on the basis of planning tasks.

\section{SCENARIo PRESUMing BASED URBAN CI EMERGENCY CAPACITY SHORTAGE ANALYZING}

\section{A. Scenario Inserting of Capacity Shortage Analysis}

In terms of scenario inserting method, this paper adopts the multi-dimension scenario space method to insert scenarios and presents scenarios with multi-dimension way. Every dimension will correspond with a smallest basic element. The scenarios of capacity shortage analysis are composed of scenario elements which are called the scenario elements of CI emergency capacity shortage. In terms of scenario elements choosing, this paper mainly considers on cascading disasters, the elements can be generalized as causing factors, affected bodies and environment.

- Causing factors. Under certain conditions, a series of causing factors can directly cause large-scale natural disasters and gradually drive the spread of disasters, which will produce secondary disasters. These causing factors mainly refer to non-artificial factors, including earthquakes, typhoons, tsunami, heavy rainfall, heavy snow, high temperature, and etc. Causing factors directly function on affected bodies. They are the blasting fuses of disasters. The bigger the variation degree of causing factors is, the higher the destruction degree is.

- Affected bodies. Causing factors function on the affected bodies. The affected bodies in this paper refer to critical infrastructure, including power grid, water grid, communication grid, and etc.

- Environment. Environment mainly includes geographical environment, geological environment, terrain environment, population density distribution, industry intensive length, and etc. Environment can be divided into two aspects. One is natural environment such as terrain, geology, temperature and humidity, wind speed and direction, water flow condition. Another one is human environment such as population distribution, industry distribution, CI conditions. That shows that different areas have different environment.

\section{B. Disaster Scenario Presuming and Response Project Simulating}

Before scenario presuming, a basic presuming scenario should be identified. Basic presuming scenario is the template of presuming scenario, including fixed scenario element values. If the decision making sources supporting capacity shortage scenario presuming are meaningless, it is hard to preset the scenarios according to decision making sources. It is much hard to assure the validity of capacity shortage analysis. Consequently, the start of capacity shortage analysis should not be blind, but should be fully considered. The scenario presuming can be viewed as a process to obtain presetting scenarios with decision rules based on the basic presuming scenarios. Common tools of identifying basic presuming scenarios include case-driven, data-driven, and etc. For instance, an area has suffered a 7 level typhoon. It caused serious consequences. The decision makers consider that they should carry out capacity shortage analysis specific to this kind of disasters, which starts the capacity shortage analysis of this kind of disasters.

On the basis of basic presuming scenarios, this paper proposes three kinds of scenario presuming methods.

- Pessimistic scenario method. Decision makers choose the worst scenarios as the presuming scenarios according to real demands based on basic presuming scenarios. Generally, this method applies to scenarios that disasters are frequent, emergency budgets are rich or emergency management requests are high.

- Positive scenario method. Decision makers choose the best scenarios as the presuming scenarios according to real demands based on basic presuming scenarios. Generally, this method applies to scenarios that disasters are not frequent, emergency budgets are low or emergency management requests are not high.

- Hierarchical scenario method. Decision makers divide the presuming scenarios into different levels according to real demands based on basic presuming scenarios. Generally, this method applies to areas that it is hard to adjust disaster frequencies, 
emergency budgets are rich and plan according to principle "input-output".

This paper uses hierarchical scenario method to reduce scenario uncertainty. On the basis of scenario presuming, decision makers design response projects as simulated projects in terms of the level of scenarios.

\section{Response Evaluation and Presuming Project Choosing}

In scenario presuming, choosing the best simulated project as presuming project by evaluating the response results of simulated projects to presetting scenarios. In the operation, value of presuming projects can be evaluated by calculating scenario threat, scenario threat reduction probability and project costs.

- Scenario threat. Scenario threat can be defined as the product of scenario influence and scenario variation. On the one hand, the bigger the scenario influence is, the bigger the threat caused by scenarios. On the other hand, the bigger the scenario variation is, the higher the probability that scenarios cause deep influence is. Consequently, scenario threat can be presented as (1).

$$
\boldsymbol{v}_{s i}=I F_{s i} \bullet\left(I F_{s i}^{U}-I F_{s i}^{L}\right)
$$

- Among them, $v_{s i}$ represents the scenario threat of $s i$, $I F_{s i}$ represents the scenario influence of $s i, I F_{s i}{ }^{U}$ $-I F_{s i}{ }^{L}$ represents the scenario variation of $s i$, $I F_{s i}{ }^{U}$ represents the maximum of scenario threat, and $I F_{s i}{ }^{L}$ represents the minimum of scenario threat.

- Scenario value of project. Scenario value of project is related to scenario threat. It refers to the reduction value of scenario threat when adopting a response project. According to the hierarchical scenario method, under different levels of scenarios, the reduction value of scenario threat is different although the project is same. Consequently, the calculation of scenario value should consider scenario levels, corresponding scenario threat and reduction value of scenario. This process can be presented as (2).

$$
V S_{j}=\sum_{i=1}^{n} v_{s i} \bullet p_{j i}, j=1,2, \ldots, m
$$

- After standardization, the process can be presented as (3).

$$
\left|V S_{j}\right|=\frac{V S_{j}}{\max \left\{V S_{j}\right\}}, j=1,2, \ldots, m
$$

Among them, $\left|V S_{j}\right|$ represents the scenario value of

response project $j, v_{s i}$ represents the scenario threat of $s i(i=1,2, \ldots, n), p_{j i}$ represents the probability that threat of scenario $s i$ is reduced when adopting response project $j$.

- Adoption value of project. Adoption value of project is not only relevant to the scenario value, but also to the adoption cost of project. When the scenario value of project is fixed, the higher of the adoption cost is, the lower the adoption value is. This process can be presented as (4).

$$
V A_{j}=\left|V S_{j}\right|-\left|c_{j}\right|, j=1,2, \ldots, m
$$

- Among them, $V A_{j}$ represents the adoption value of response project $j,\left|c_{j}\right|$ represents the standardized value of adoption cost of project $j$.

\section{Capacity Shortage Evaluation and Identification}

Comparing the task implementation in real condition with that in presuming project, the next stage identifies capacity shortage problems among the tasks. The work of this stage involves two parts of contents that are the item identification of capacity shortage evaluation and the identification regulation design of capacity shortage evaluation. Capacity shortage identification can be viewed as the process that adjusting whether the evaluation items are capacity shortage problems or not according to the identification regulations.

At the aspect of evaluation items, this paper adopts the mapping relationship "response task failure-emergency capacity shortage". At the aspect of identification regulation, this paper adopts hierarchical rating method, in which we invite field experts rating the capacity shortage degree by comparing available emergency capacity with the capacity requirements in the presuming projects, based on setting the adjustment threshold of capacity shortage. Among them, at the aspect of capacity shortage threshold setting, it is identified generally according to emergency management requirements.

\section{CASE STUDY}

In order to verify the feasibility and effectiveness of scenario presuming method, this paper designs a case study under the background of south China responding typhoon disaster. An area of south China has suffered 12-level typhoon, the economic losses up to 30 million Yuan. According to this simulated disaster, presuming the possible future scenarios and simulating corresponding response projects. According to the severe degree of scenarios, they can be divided into S1 (Severe), S2 (Relatively Severe) and S3 (Quite Severe). 


\section{A. Scenario-Response Simulation.}

Presuming disaster scenarios.

Presuming scenarios S1: Typhoon boards at the neighboring city. Affected by it, the wind speed of the area in coastal region can reach 12-level. The areas suffer continuous heavy rain, the estimated economic values can reach 10 million.

Presuming scenarios S2: Typhoon boards at the edge of the area. Affected by it, the wind speed of the area in coastal region can reach 15-level. The areas suffer continuous heavy rain, the estimated economic values can reach 20 million.

Presuming scenarios S3: Typhoon boards at the area. Affected by it, the wind speed of the area in coastal region can reach 17-level. The areas suffer continuous heavy rain, and the estimated economic values can reach 30 million.

Simulating response projects.

Simulated project A1: Designing 1 to 2 repair projects. All of the storage centers of emergency materials store little materials (Reach the basic repair requirements), and the investment cost is 50 million.

Simulated project A2: Designing 2 to 3 repair projects. All of the storage centers of emergency materials store relatively enough materials (Have some supply on the basis of basic requirements), and the investment cost is 70 million.

Simulated project A3: Designing 3 to 4 repair projects. All of the storage centers of emergency materials store large amount of materials (Have at least twice of the amount of basic requirements), and the investment cost is 50 million.

\section{B. Presuming Project Choosing.}

According to $(1) \sim(4)$, the calculation results are shown in Tab.1 4 .

TABLE I. SCENARIO THREAT SUMMARY

\begin{tabular}{|c|c|c|c|c|}
\hline & $I F_{s i}$ (10 thousand) & $I F_{s i}{ }^{L}$ & $I F_{s i}{ }^{U}$ & $v_{s i}$ \\
\hline $\mathrm{S}_{1}$ & 1 & 0.9 & 1.1 & 0.2 \\
\hline $\mathrm{S}_{2}$ & 2 & 1.9 & 2.2 & 0.6 \\
\hline $\mathrm{S}_{3}$ & 3 & 2.7 & 3.5 & 2.4 \\
\hline
\end{tabular}

TABLE II. The Probability of the ThreAt OF SCENARIo $s i$ WheN AdOPTING PROJECT $j$

\begin{tabular}{|l|l|l|l|}
\hline & $\mathbf{S}_{1}$ & $\mathbf{S}_{2}$ & $\mathbf{S}_{\mathbf{3}}$ \\
\hline $\mathrm{A}_{1}$ & 0.5 & 0.3 & 0.1 \\
\hline $\mathrm{A}_{2}$ & 0.7 & 0.5 & 0.3 \\
\hline $\mathrm{A}_{3}$ & 0.9 & 0.7 & 0.5 \\
\hline
\end{tabular}

TABLE III. Calculation Results of Project Value

\begin{tabular}{|c|c|c|c|c|}
\hline & $V S_{j}$ & $\left|V S_{j}\right|$ & $\left|c_{j}\right|$ & $V A_{j}$ \\
\hline $\mathrm{A}_{1}$ & 0.52 & 0.289 & 0.2 & 0.089 \\
\hline $\mathrm{A}_{2}$ & 1.16 & 0.644 & 0.5 & 0.144 \\
\hline $\mathrm{A}_{3}$ & 1.8 & 1 & 1.0 & 0.000 \\
\hline
\end{tabular}

To sum up, project $\mathrm{A} 2$ is the best project.

\section{Capacity Shortage Identification.}

Tab. 4 displays the task implementation results in real condition and in project $\mathrm{A} 2$. We invite experts to rate according to the results.

We invite 5 experts to carry out the evaluation. All experts make semantic adjustments of the capacity shortage degree of every task. Then, we calculate the fuzzy scores of the capacity shortage of real condition that are $\mathrm{T} 1(0,0,0.25)$, $\mathrm{T} 2(0,0.10,0.35), \quad \mathrm{T} 3(0.10,0.45,0.60), \quad \mathrm{T} 4(0.20,0.55,0.70)$, $\mathrm{T} 5(0.30,0.65,0.70)$, T6 $(0.30,0.65,0.80)$, T7(0.10,0.45,0.60). Choosing 0.5 as the cut set level, the scores can be converted into interval scores that are T1 $[0,0.125], \mathrm{T} 2[0.050,0.225]$, T3[0.275,0.525], T4[0.375,0.625], T5[0.475,0.675], T6[0.475,0.725], T7[0.275,0.525].

Choosing 0.5 as the degree threshold of capacity shortage, the following items are identified as capacity shortage problems that are "Disaster warning(T1)", "Design repair projects(T2)", "Dispatch repair vehicles(T3)", "Dispatch repair teams(T4)", "Investment(T5)", "Set materials dispatching center(T6)", "Removable power supply unit(T7)".

TABLE IV. TASK IMPLEMENTATION RESULTS IN REAL CONDITION AND IN PROJECT $\mathrm{A}_{2}$

\begin{tabular}{|l|l|l|}
\hline Response tasks & Real condition & Project $\mathbf{A}_{2}$ \\
\hline $\begin{array}{l}\text { Disaster } \\
\text { warning }\left(\mathrm{T}_{1}\right)\end{array}$ & $\begin{array}{l}\text { Starting emergency plan } \\
\text { and publishing warning } \\
\text { information }\end{array}$ & $\begin{array}{l}\text { Starting emergency plan } \\
\text { and publishing warning } \\
\text { information }\end{array}$ \\
\hline $\begin{array}{l}\text { Design repair } \\
\text { projects }\left(\mathrm{T}_{2}\right)\end{array}$ & $\begin{array}{l}\text { Identifying repair time, } \\
\text { range, investment, etc. 1 } \\
\text { project. }\end{array}$ & $\begin{array}{l}\text { Identifying repair time, } \\
\text { range, investment, etc. 2 } \\
\text { to 3 projects. }\end{array}$ \\
\hline $\begin{array}{l}\text { Dispatch repair } \\
\text { vehicles }\left(\mathrm{T}_{3}\right)\end{array}$ & $3 \sim 5$ vehicles & $5 \sim 10$ vehicles \\
\hline $\begin{array}{l}\text { Dispatch repair } \\
\text { teams }\left(\mathrm{T}_{4}\right)\end{array}$ & $5 \sim 10$ teams & 10 20 teams \\
\hline Investment $\left(\mathrm{T}_{5}\right)$ & 50 million Yuan & 7000 million Yuan \\
\hline $\begin{array}{l}\text { Set materials } \\
\text { dispatching } \\
\text { center }\left(\mathrm{T}_{6}\right)\end{array}$ & $1 \sim 2$ centers & 5 centers \\
\hline
\end{tabular}

\section{CONCLUSION}

Analyzing CI capacity from the perspective of capacity shortage help directly discover the weak links of response system. Under the background of scenario uncertain, it is hard to directly predict the scenarios of future disasters, causing difficulty of presuming scenarios for capacity shortage analysis. Focus on the problem, this paper proposes a scenario presuming based method for analyzing capacity shortage in urban CI. Scenario presuming can be divided into 4 stages that are scenario inserting of capacity shortage analysis, disaster scenario presuming and response project simulating, response evaluation and presuming project choosing and capacity shortage evaluation and identification. In order to verify the feasibility and effectiveness of the method, a case study is proposed under the background of south China responding typhoon disaster. 


\section{ACKNOWLEDGMENT}

Foundation Project: Emergency Management Major Research Project (91024028, 91024031, 91324018); General Program (71172156, 71473058) supported by National Natural Science Foundation of China.

\section{REFERENCES}

[1] David Rehak, Jiri Markuci, Martin Hromada, Karla Barcova. "Quantitative evaluation of the synergistic effects of failures in a critical infrastructure system," International Journal of Critical Infrastructure Protection, 14, 2016, pp. 3-17.
[2] Qin-Ying Sun, Xiang-Yang Li, Feng Yu. "Designing the emergency continuity management for urban infrastructures: A conceptual framework for coping with catastrophe," International Journal of Critical Infrastructure Protection, 13, 2016, pp: 28-35.

[3] Ronald Perry, Michael Linder. "Emergency response preparedness: guiding principles for preparedness planning," China Emergency Management, (10), 2011, pp: 19-25.

[4] Xinhua News Agency. Continuous operations Go all out-Fujian responses the typhoon Megi. http://www.gov.cn/xinwen/ 201609/28/content_5112869.htm, 9.29, 2016.

[5] Liu T M. "Vulnerability-essential reasons of emergency incidents emerge and develop," China Emergency Management, (10), 2010, pp: 32-35. 